\title{
Correlations between Cotton Characteristics in Greek Multi-environments
}

\author{
Vasileios Greveniotis (Corresponding author) \\ Technological Education Institute of Thessaly, Department of Agricultural Technology, \\ 41110 Larissa, Greece. E-mail: vgreveni@mail.com, vgreveni@teilar.gr
}

\section{Evangelia Sioki}

Hellenic Agricultural Organization - "Demeter", National Center For Quality Control, Classification \& Standardization of Cotton, 1st km Karditsa-Mitropolis, 43100 Karditsa, Greece.

\section{Constantinos G. Ipsilandis}

Regional Administration of Central Macedonia, Department of Agricultural Economy, 54627 Thessaloniki, Greece

Received: November 9, 2017 Accepted: November 23 , 2017 Published: November 30, 2017 doi:10.5296/jas.v5i4.12121 URL: https://doi.org/10.5296/jas.v5i4.12121

\begin{abstract}
Correlations of data provided by AFIS and HVI were performed under a multi-location evaluation of cotton fiber characteristics in the Greek environment. Four main cotton-production Greek regions were selected and the five most cultivated commercial upland cotton (Gossypium hirsutum L.) cultivars were used for evaluation of fiber length and short fiber characteristics by AFIS and HVI instruments. Each cultivar was sown in 16 fields and 80 fields in total were used for all cultivars. Both HVI and AFIS gave reliable data concerning fiber length and short fiber estimations. High positive and statistically significant correlations between the two instruments were found indicating the similarity of final measurements. Fiber length estimations can be performed with higher accuracy than short fiber estimations, because CV values were lower for both instruments. HVI and AFIS showed different advantages in estimating fiber length and short fiber characteristics. Measurements of AFIS on fiber length had a smaller range between maximum and minimum values, but HVI showed lower CV\% which is more useful for breeders, since it may indicate gene
\end{abstract}


fixation that ensures easier breeding procedure. For short fibers, AFIS also showed a smaller range between maximum and minimum values and HVI showed lower CV\%. Graphical comparisons between HVI and AFIS measurements for fiber length and short fibers showed that HVI had a more pattern with lower fluctuations than AFIS.

Keywords: multi-location, AFIS, HVI, fiber length

\section{Introduction}

Upland cotton (Gossypium hirsutum L.), is one of the main cultivations in Greece, with four main regions consisting a mega-environment (Baxevanos et al., 2006; 2013; Greveniotis and Sioki, 2017). Improvement in fiber quality is the primary objective for cotton breeders, coping with the lack of reliable methods to measure fiber characteristics. Technical support came by High Volume Instrument-HVI in the late 1960s and Advanced Fiber Information System-AFIS in the early 1980s. Both commercially recognized for cotton fiber measurements (Kelly et al., 2012; Wu and Wang, 2015). Many characteristics may define fiber quality in cotton with fiber length, short fibers and fiber strength being essential (Baxevanos et al., 2013). Previous research recognized the need for additional information about AFIS properties and data accumulation on its usefulness (Meredith et al., 1996). These two instruments are fully automated and measure many fiber characteristics in a very short time, with different use in textile industry (Nair et al., 2009). Based on the different technical specifications of these instruments a few researchers tried to compare measurements of fiber characteristics in order to provide more data for cotton breeders (Cheng and Cheng, 2002). Cotton fiber length and fiber content are the main factors studied by researchers because of the usefulness in textile industry and the techniques used during ginning (Ebaido, 2014). In our days fiber length is the main characteristic that cotton breeders are trying to improve (Karademir, 2010). In general, many breeders simply ignore fiber measurements because the lack of calibration for HVI. Additionally, data presented by various researchers are not correlated to processing needs of ginners and textile industry, plus the fact that this kind of measurements has never been formally analyzed by a certain statistical model (Munro, 1987; Behery, 1993).

Fiber quality is depended on various traits, such as fiber length, strength, uniformity etc. (Poehlman and Sleper, 1995) and thus it depends on both genetic and environmental factors (Bradow and Davidonis, 2000) and also on cultivation techniques and textile processing (Anthony, 1999). In our study, correlations of data provided by AFIS and HVI were performed under a multi-location evaluation of cotton fiber characteristics in the Greek environment.

\section{Materials and Methods}

Four main cotton-production Greek regions were selected as different environments (Greveniotis and Sioki, 2017), i.e. Thessaly, Sterea Ellas, Macedonia and Thrace. The five most cultivated commercial upland cotton (Gossypium hirsutum L.) cultivars were used for evaluation, i.e. DP332 and DP377 proprietary of Monsanto Co, ST402 proprietary of Pioneer Hi-Bred, CELIA and ELSA proprietary of Bayer Crop Science. These cultivars are varying in 
origin and maturity class. Four fields in each of four regions were chosen for sowing each cultivar separately, in order to evaluate different soil types and environmental conditions. Thus, each cultivar was sown in 16 fields and 80 fields in total were used for all cultivars. Each plot area was greater than 1 ha. Rows spaced $96 \mathrm{~cm}$ apart and plant density was on average 15 plants per $\mathrm{m}^{2}$. Crop management practices for each location were consistent with typical agronomic practices in the region and included full irrigation applied with sprinklers from mid-June until 20 days prior to harvest, spraying for pests as required and weed control by pre-planting herbicides.

Four samples from each field were collected to analyze fiber quality traits at the accredited laboratory of National Center of Cotton, in Karditsa, Greece. Before testing cotton samples were conditioned for at least 24 hours at $65 \pm 2 \% \mathrm{RH}$ and $21 \pm 1{ }^{\circ} \mathrm{C}$ (ASTM, 2015). Fiber traits involved: mean length by weight (L-w) in mm, upper quartile length by weight (UQL-w) in mm, mean length by number (L-n) in $\mathrm{mm}$, short fiber content by weight \% (SFC-w), short fiber content by number \% (SFC-n), upper half mean length (UHML) in mm and short fiber index $\%$ (SFI). The instruments and methods used to measure cotton fiber characteristics included High Volume Instrument - HVI by Uster Technologies AG, Uster, Switzerland (for the two last fiber characteristics) and Advanced Fiber Information System - AFIS also by the same manufacturer Uster Technologies AG, Uster, Switzerland (for all the rest characteristics).

UHML: Upper Half Mean Length: mean length by weight of the longer 50\% of fibers (HVI). L-w: Average fiber length by weight of all the cotton fibers in the sample (AFIS). UQL-w: Upper Quartile Length by weight: length exceeded by $25 \%$ of the fibers (AFIS). L-n: Average fiber length by number of all cotton fibers in the sample (AFIS). SFI: Short fiber index: percentage of fibers shorter than $1 / 2$ inch or $12.7 \mathrm{~mm}$ (HVI). SFC-w: Percent of all fibers in a cotton sample that are shorter than $12.7 \mathrm{~mm}(0.5 \mathrm{in}$.) by weight (AFIS). SFC-n: Percent of all fibers in a cotton sample that are shorter than $12.7 \mathrm{~mm}(0.5 \mathrm{in}$.) by number (AFIS).

General statistics (MIN: minimum, MAX: maximum, Mean: the mean value, Std. Dev. is the standard deviation and CV\% is the coefficient of variation) were calculated and correlations between fiber traits were performed according to Pearson r- coefficient (Steel and Torrie, 1980).

\section{Results}

Correlations between fiber characteristics provided using the two methods were computed and presented in Tables 1 and 2. Comparing HVI and AFIS, the most significant positive correlation was between upper half mean length (UHML) and upper quartile length by weight (UQL-w) and found 0.86. Also comparing HVI and AFIS, short fiber index (SFI) was positively correlated to short fiber content by weight (SFC-w) and found 0.52. All correlations were found statistically significant at level 0.01 and some of them were very high (from 0.88 to 0.98 ). 
Table 1. Correlation coefficients between the UHML, L-w, UQL-w and L-n

\begin{tabular}{|l|l|l|l|}
\hline & UHML & L-w & UQL-w \\
\hline L-w & $0.82 * *$ & & \\
\hline UQL-w & $0.86 * *$ & $0.97 * *$ & \\
\hline L-n & $0.72 * *$ & $0.96 * *$ & $0.88 * *$ \\
\hline
\end{tabular}

** Correlation is significant at the 0.01 level

Table 2. Correlation coefficients between the SF, SFC-w and SFC-n

\begin{tabular}{|l|l|l|}
\hline & SFI & SFC-w \\
\hline SFC-w & $0.52 * *$ & \\
\hline SFC-n & $0.42 * *$ & $0.98 * *$ \\
\hline
\end{tabular}

** Correlation is significant at the 0.01 level

For general statistics presented in Table 3, measurements of AFIS on fiber length showed a smaller range between maximum and minimum values (within a range of 4.2), but HVI showed the lower CV\% at 3.68. For short fibers, AFIS also showed a smaller range between maximum and minimum values, but HVI showed the lower CV\% at 13.67 (Table 4). SFI mean found 7.9, while SFC-w and SFC-n were 3.5 and 12.2 respectively.

Table 3. General statistics (MIN: minimum, MAX: maximum, Mean: the mean value, Std. Dev. is the standard deviation and CV\% is the coefficient of variation) per characteristic (UHML, L-w, UQL-w and L-n)

\begin{tabular}{|l|c|c|c|c|}
\hline & HVI & \multicolumn{3}{|c|}{ AFIS } \\
\hline & UHML & L-w & UQL-w & L-n \\
\hline MIN & 25.6 & 24.0 & 28.3 & 20.8 \\
\hline MAX & 30.4 & 27.5 & 32.5 & 23.7 \\
\hline MEAN & 28.5 & 26.8 & 31.2 & 23.5 \\
\hline Std. Dev. & 1.05 & 1.17 & 1.29 & 1.25 \\
\hline CV\% & 3.68 & 4.37 & 4.13 & 5.32 \\
\hline
\end{tabular}




\section{Macrothink}

Table 4. General statistics (MIN: minimum, MAX: maximum, Mean: the mean value, Std.

Dev. is the standard deviation and CV\% is the coefficient of variation) per characteristic (SFI, SFC-w, SFC-n)

\begin{tabular}{|l|c|c|c|}
\hline & HVI & \multicolumn{2}{|c|}{ AFIS } \\
\hline & SFI & SFC-w & SFC-n \\
\hline MIN & 6.3 & 2.3 & 8.8 \\
\hline MAX & 13.3 & 5.2 & 5.2 \\
\hline MEAN & 7.9 & 3.5 & 12.2 \\
\hline Std. Dev. & 1.08 & 0.83 & 2.30 \\
\hline CV\% & 13.67 & 23.71 & 18.85 \\
\hline
\end{tabular}

From Figures 1 and 2, it is obvious that HVI measurements for fiber length and short fibers showed minimum fluctuations, while AFIS showed intense fluctuations.

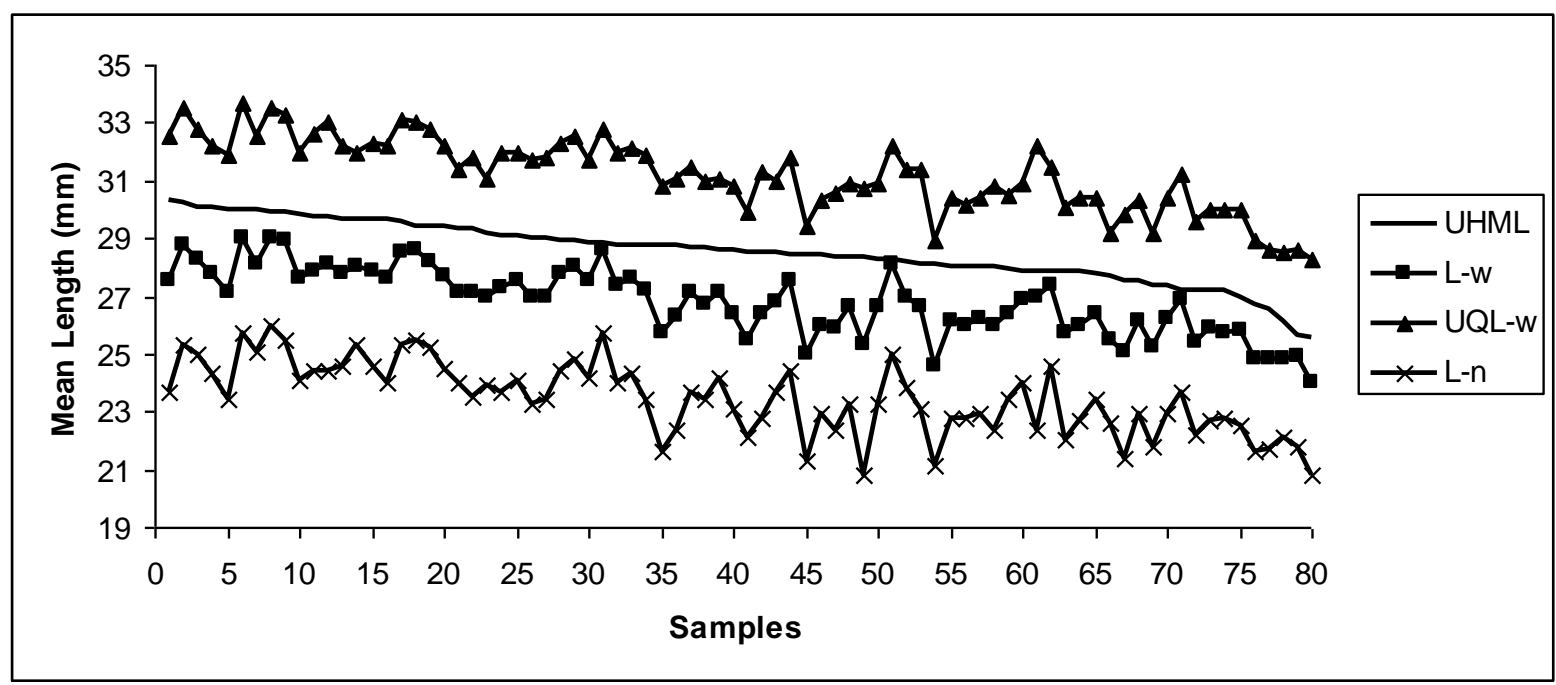

Figure 1. A comparison of the mean length measurements (UHML, L-w, UQL-w and L-n) 


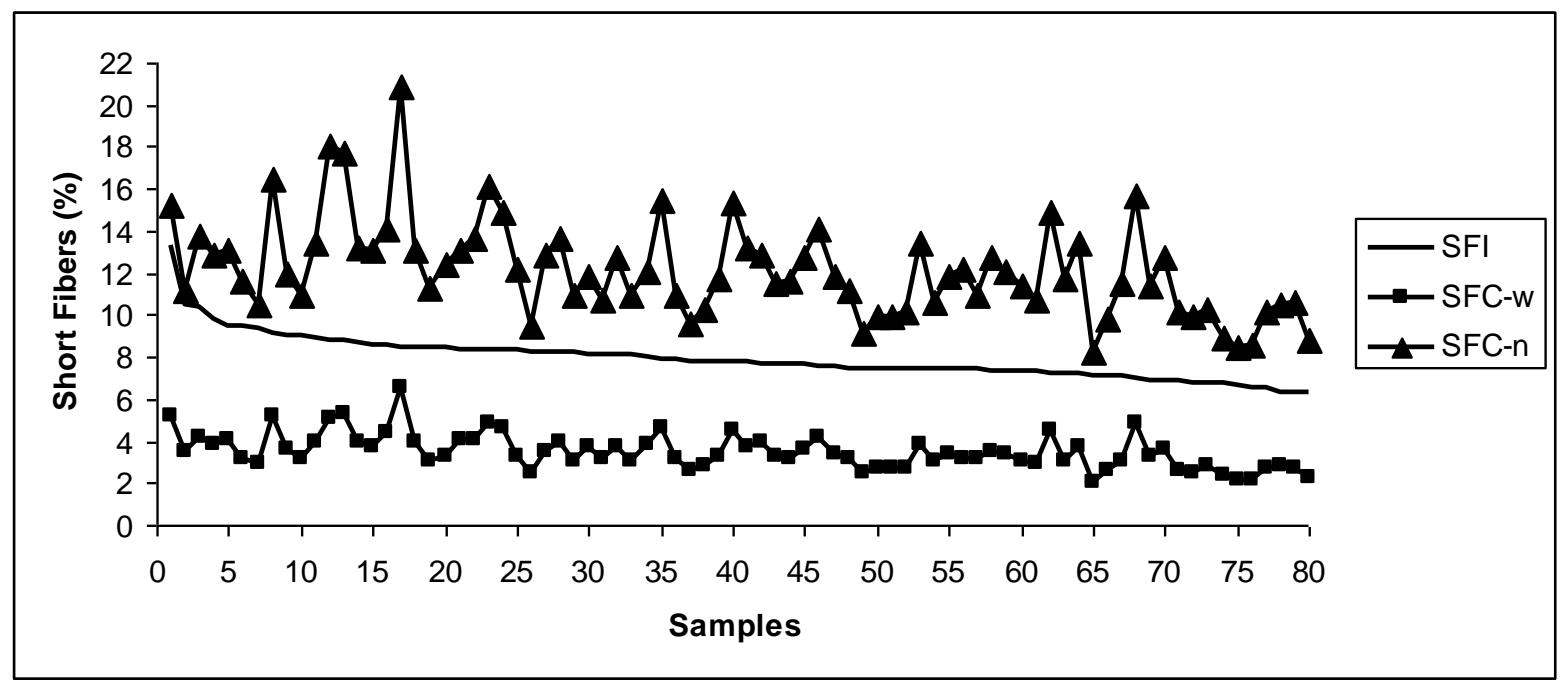

Figure 2. A comparison of the mean short fiber measurements (SFI, SFC-w, SFC-n)

\section{Discussion}

HVI and AFIS estimations on fiber length and short fibers are essential for the textile industry. These two fiber characteristics are the main factors of fiber quality for industrial use (Karademir, 2010). Thus, a comparison between these two instruments is needed in order to decode their measurements for breeding and practical purposes (Ebaido, 2014).

Carrying out tests in different instruments for measurement of fiber length distributions may result in the most accurate and reproducible results for breeding purposes. In our study, UHML length measurements from HVI were highly correlated to UQL-w, L-w and L-n measurements from AFIS. Even higher and statistically significant were correlations between all AFIS measurements. Statistically significant were also correlations between HVI measurements of short fibers (SFI) and AFIS measurements (SFC-w and SFC-n), but r-coefficients were relatively. High and positive correlations are also mentioned by other researchers (Ebaido, 2014), indicating that indeed the two instruments are capable to read similar results for fiber length and short fibers. We found that AFIS readings are almost the same for the three different fiber length estimations (UQL-w, L-w and L-n) and positively correlated to HVI measurements (UHML). For short fibers, AFIS readings reached a correlation near 1, but between AFIS and HVI correlations were low indicating a departure from linearity.

General (descriptive) statistics showed that measurements of AFIS on fiber length had a smaller range between maximum and minimum values, but HVI showed lower CV\%. For short fibers, AFIS also showed a smaller range between maximum and minimum values, but HVI showed lower CV\%. Graphical comparisons between HVI and AFIS measurements for fiber length and short fibers showed that HVI had a more pattern with lower fluctuations than AFIS. Similar results were reported by Thibodeaux et al. (2008), Kelly et al. (2012), Ebaido (2014) indicating a stability (and reliability) of estimations from the two different instruments. Thibodeaux et al. (2008) found some poor correlations between HVI and AFIS estimations on 
short fibers and they concluded that a quadratic model might describe better their relationship than a linear one. Cui et al. (2003) showed a higher correlation between HVI and AFIS estimations on short fibers, but they also added that there must be a better uniformity of the samples used. From our findings, fiber length estimations can be performed with higher accuracy than short fiber estimations, because Coefficient of variation (CV\%) values were lower for both instruments. HVI showed the lowest CV values and the lower fluctuations, revealing a high reliability in estimating fiber characteristics. CV is considered a useful parameter for cotton breeders. Fasoulas (1988) presented the main factors affecting selection progress and depicted the role of $\mathrm{CV}$. Under a breeding program the reduction of CV values through selection reveals gene fixation and lack of segregation in selected lines which tend to be more uniform (Fasoulas, 1988; Greveniotis and Fasoula, 2016). Low CV values, are indicating stability of performance and low environmental effects and under intense breeding accumulation of favorable additive genes (Fasoulas, 1988). AFIS showed more "tight" measurements and revealed a fluctuating graphical model of data similar to Ebaido (2014) findings who also reported fluctuations for AFIS measurements in comparison to HVI.

\section{Conclusions}

The main conclusion is that both HVI and AFIS gave reliable data concerning fiber length and short fiber estimations. High positive and statistically significant correlations between the two instruments were found indicating the similarity of final measurements. Fiber length estimations can be performed with higher accuracy than short fiber estimations, because CV values were lower for both instruments. HVI and AFIS showed different advantages in estimating fiber length and short fiber characteristics. Descriptive statistics showed that measurements of AFIS on fiber length had a smaller range between maximum and minimum values, but HVI showed lower CV\% which is more useful for breeders, since it may indicate gene fixation that ensures easier breeding procedure. For short fibers, AFIS also showed a smaller range between maximum and minimum values, but HVI showed lower CV\%. Graphical comparisons between HVI and AFIS measurements for fiber length and short fibers showed that HVI had a more pattern with lower fluctuations than AFIS.

\section{Acknowledgement}

Research is part of the action "Research and Technology Development Innovation Projects AgroETAK", MIS 453350, in the framework of O.P. "Human Resources Development", co-funded by ESF and National funds (NSRF 2007-2014), coordinated by the Hellenic Agricultural Organization ELGO "DEMETER".

This paper is dedicated to late professors A. C. Fasoulas and St. Zotis for their contribution in plant breeding in Greece.

\section{References}

Anthony, W. S. (1999). Postharvest management of fiber quality. In A. S. Basra (Ed.), Cotton fibers, developmental biology, quality improvement, and textile processing (pp. 293-337). New York: Food Products Press. 
American Society of Testing Materials [ASTM]. (2015). Standard Practice for Conditioning and Testing Textiles, ASTM D1776/D1776M-15. Book of ASTM Standards, ASTM International, West Conshohocken, PA.

Baxevanos, D., Goulas, C., Tzortzios, S., \& Mavromatis, A. (2006). Grouping Greek cotton (Gossypium hirsutum L.) trial locations into megaenvironmets. Agricultural Research, 29(2), 35-48 (in Greek with English summary).

Baxevanos, D., Tsialtas, I. T., \& Goulas, C. (2013). Repeatability and stability analysis for fiber traits in upland cotton (Gossypium hirsutum L.). Australian Journal of Crop Sciience, 7(10), 1423-1429.

Behery, H. M. (1993). Short-fiber content and uniformity index in cotton. International Cotton Advisory Committee and Center for Agriculture and Biosciences Review Article 4. Washington, D.C.: 1-40.

Bradow, J. M., \& Davidonis, G. H. (2000). Quantification of fiber quality and the cotton production-processing interface: a physiologist's perspective. Journal of Cotton Science, 4, 34-64.

Cheng, Y. S. J., \& Cheng, K. P. S. (2002). A comparison of HVI, AFIS and traditional cotton testing method. IFFTI International Conference 2002: Fashion and Textiles: the New Frontiers Design, Technology and Business: 7-9 Nov. 2002, Hong Kong: 624-627.

Cui, X., Calamari, T., Robert, K. Q., Price, J. B., \& Watson, M. D. (2003). Measuring the short fiber content of cotton. Textile Research Journal, 73(10), 891-895.

https://doi.org/10.1177/004051750307301007

Ebaido, I. A. M. (2014). An evaluation for cotton fiber length distribution measurements of different methods. International Journal of Fiber and Textile Research, 4(1), 5-11

Fasoulas, A. C. (1988). The Honeycomb Methodology of Plant Breeding. Thessaloniki, Greece. A. Altidjis Publ.

Greveniotis V., \& Fasoula, V.A. (2016). Application of prognostic breeding in maize. Crop and Pasture Science, 67, 605-620. http://dx.doi.org/10.1071/CP15206

Greveniotis, V., \& Sioki, E. (2017). Genotype by environment interactions on cotton fiber traits and their implications on variety recommendation. Journal of Agricultural Studies, 5(2), 86-106. http://dx.doi.org/10.5296/jas.v5i2.10762.

Karademir, E., Karademir, C., Ekinci, R., \& Gencer, O. (2010). Relationship between Yield, Fiber Length and other Fiber-Related Traits in Advanced Cotton Strains. Notulae Botanicae Horti Agrobotanici Cluj-Napoca, 3(3), 111 - 116.

Kelly, C., Hequet, E., \& Dever J. (2012). Interpretation of AFIS and HVI fiber property measurements in breeding for cotton fiber quality improvement. Journal of Cotton Science, 16: $1-16$.

Meredith, W. R., Jr., Sasser, P. E., \& Rayburn S. T. (1996). Regional high quality fiber 


\section{Macrothink}

Journal of Agricultural Studies

ISSN 2166-0379

2017, Vol. 5, No. 4

properties as measured by conventional and AFIS methods. In: Proc. Beltwide Cotton Conf., Nashville TN. 9-12 Jan. 1996. Natl. Cotton Counc. Am., Memphis, TN: 1681-1684.

Munro, J. M. (1987). Cotton, 2nd ed. Longman - Wiley, New York.

Nair, A. U., Nachane, R. P., \& Patwardhan, B. A. (2009). Comparative study of different test methods used for the measurement of physical properties of cotton. Indian Journal of Fiber \& Textile Research, 34, 352-358

Poehlman, J. M., \& Sleper, D. A. (1995). Breeding field crops. Iowa State Univ. Press.

Steel, R. G. D., \& Torrie, H. (1980). Principles and procedures of statistics: A biometrical approach., 2nd ed. McGraw Hill Book Co., New York.

Thibodeaux, D., Senter, H., Knowlton, J. L., McAlister, D., \& Cui, X. (2008). A comparison of methods for measuring the short fiber content of cotton. Journal of Cotton Science, 12(3), 298-305.

Wu, H., \& Wang, F. (2013). Image measuring method for fiber length measurements. Industria textile, 64(6), 321-326.

\section{Copyright Disclaimer}

Copyright for this article is retained by the author(s), with first publication rights granted to the journal.

This is an open-access article distributed under the terms and conditions of the Creative Commons Attribution license (http://creativecommons.org/licenses/by/4.0/). 